\title{
Uma cosmopolítica afroindígena da performance no culto aos Caboclos $^{1}$
}

Fábio Alex Ferreira da Silva ${ }^{2}$

\section{Resumo}

Caboclos, entidades espirituais com características indígenas e regionais, inserem-se no Candomblé em uma perspectiva liminar. Suas presenças evocam formas de comportamento sociorrituais nas fronteiras de tradições reterritorializadas. Por um lado, o termo foi utilizado para denominar um resultado da mistura entre indígenas e brancos, operando uma diluição da identidade e apagamento étnico através da mestiçagem. Por outro, as expressões de espiritualidades indígenas nas religiões afro-brasileiras foram pensadas sob a formulação teórica do sincretismo. No entanto, articulando uma contramestiçagem, as ações das entidades operam um engajamento na transformação do significado da categoria Caboclo, antes utilizada para denominá-las em campos teóricos da mistura. Ao abordá-los na perspectiva dos estudos da performance, com ênfase no "aqui e agora", enfatizamos as possiblidades de uma composição que estabelece relações entre suas ações e poderes a um conjunto de articulações de um imaginário social. A performance possibilita um devir da experiência, um material em movimento. No culto aos caboclos, agenciam-se poderes a partir da função integradora do ritual, estabelecendo um acesso a domínios e ancestralidades indígenas. Mais do que representações, nos terreiros são mobilizados modos de relação com uma possibilidade de cultura indígena viva na ação das entidades. Suas manifestações são o encontro entre mundos - um encontro "afroindígena" experiências narradas e atualizadas nas práticas rituais. Contrabalanceando formulações teóricas dos campos de estudos da performance e estudos das religiões afro-brasileiras, buscamos analisar o repertório utilizado na restauração de comportamentos dos caboclos, considerando sua manifestação como um ato cosmopolítico. A manifestação das entidades, afirmando uma identidade indígena, apresenta homologias com processos de etnogênese de povos indígenas do Nordeste. Partindo da premissa de que na performance o "como se" não se diferencia do "é", utilizamos a categoria "performados" para designar e propor uma possível leitura da apresentação dos Caboclos nos candomblés.

1 Uma versão preliminar deste artigo foi apresentada no VI Congreso de la Asociación Latinoamericana de Antropología (ALA), em 2020, e posteriormente discutida com colegas no Grupo de Estudos em Oralidade e Performance (Gesto), vinculado à UFSC. Agradeço os comentários e observações realizadas por colegas nessas ocasiões.

2 Doutorando em Antropologia Social na Universidade Federal de Santa Catarina. E-mail: xfabioalex@gmail.com. 


\section{Palavras-chave}

Culto aos caboclos. Performance afroindígena. Cosmopolítica.

\section{Abstract}

Caboclos, spiritual entities with indigenous and regional characteristics, are part of Candomblé in a liminal perspective. Their presence evokes forms of socio-ritual behavior on the borders of reterritorialized traditions. On the one hand, the term was used to describe a result of the cross between indigenous and white people, operating a dilution of ethnic identity and erasure through miscegenation. On the other hand, the expressions of indigenous spiritualities in Afro-Brazilian religions were conceived under the theoretical formulation of syncretism. However, articulating a counter-mestizaje, the entities' actions operate an engagement in the transformation of the meaning of the Caboclo category, previously used to name them in this cross' theoretical fields. By addressing them from the perspective of performance studies, with an emphasis on the "here and now", we emphasize the possibilities of a composition that establishes relationships between their actions and powers to a set of articulations of a social imaginary. Performance makes possible a becoming of experience, a material in motion. In the cult of the Caboclos, powers are managed based on the integrative function of the ritual, establishing access to indigenous domains and ancestry. More than representations, in the terreiros, ways of relating to a possibility of living indigenous culture in the action of the entities are mobilized. Its manifestations is the meeting between worlds - an "Afro-Indigenous" meeting - experiences narrated and updated in ritual practices. Counterbalancing theoretical formulations from the fields of performance studies and studies of Afro-Brazilian religions, we seek to analyze the repertoire used in the restoration of Caboclos' behavior, considering its manifestation as a cosmopolitical act. The manifestation of the entities, asserting an indigenous identity, shows homologies with processes of ethnogenesis of indigenous peoples from the Northeast of Brazil. Starting from the premise that in performance the "as if" is not different from the "is", we use the category "performed" to designate and propose a possible reading of the Caboclos performance in candomblés.

\section{Keywords}

Caboclo cult. Afro-Indigenous performance. Cosmopolitics. 


\section{Os Caboclos nos candomblés: processo de identificação indígena}

El cosmos, tal como figura en el término cosmopolítica, designa lo desconocido de estos mundos múltiples, divergentes; las articulaciones de las que podrían llegar a ser capaces, contra la tentación de una paz que se quisiera final, ecuménica, en el sentido en que una trascendencia tendría el poder de exigirle a lo que diverge que se reconozca como una expresión meramente particular de lo que constituye el punto de convergencia de todos. (STENGERS, 2014, p. 21).

O termo "caboclos", no universo das religiões afro-brasileiras, abarca um conjunto de entidades espirituais com características indígenas e regionais. Essas entidades são compreendidas geralmente enquanto expressão da religiosidade indígena com as diversas modalidades de cultos afro-brasileiros. A composição de práticas religiosas que abarcam notadamente uma heterogeneidade ritual, como no caso apresentado, é geralmente abordada a partir da formulação teórica do sincretismo - apontando para uma homogeneização da diversidade da prática religiosa numa síntese ritual. No entanto, nosso objetivo será utilizar pressupostos da teoria da contramestiçagem (FLAKSMAN, 2017; GOLDMAN, 2015, 2017) para compreender os seus modos de ajuntamento, orientando-se pela concepção de que a interação entre distintas práticas religiosas não "supõe que o destino inelutável de qualquer agenciamento entre diferenças seja a homogeneidade, quer essa se manifeste por depuração e purificação, quer por mistura e fusão" (GOLDMAN, 2017, p.15), elaborando assim uma proposta de compreensão que não se reduza de antemão a identidade a um modelo homogeneizante como resultado de uma mistura.

Embora "caboclo" refira-se semanticamente à mistura entre o índio e o branco colonizador, e nesse sentido torne-se uma categoria que articula concepções teóricas do campo da "mestiçagem" e do "sincretismo", no contexto do candomblé o termo adquire outro valor, sendo utilizado para designar uma entidade espiritual propriamente indígena ${ }^{3}$.

Ainda que "caboclo" e "índio" sejam termos que expressam classificações identitárias diferenciadas, e algumas vezes opostas, sendo em alguns casos "o

\footnotetext{
${ }^{3}$ Mesmo os boiadeiros e capangueiros, que são reconhecidos como "caboclos de couro", diferenciando-os dos "caboclos de pena", são também expressões de entidades indígenas, ainda que com características diferenciadas. O fato explica-se pela ampla utilização de mão de obra indígena no processo de interiorização da colonização através da criação de gado, eram eles a força de trabalho empregada como vaqueiros.
} 
termo 'caboclo' utilizado para designar 'não índio' ou 'índio misturado'" (ALARCON, 2013, p.27), as suas utilizações variam segundo compreensões cosmopolíticas da mestiçagem e servem para que os grupos sociais abarcados por sua denominação se definam, ou sejam definidos, como mais ou menos indígenas diante de determinadas situações de conflito. Como observa Lima (1999):

Caboclo e índio são termos equivalentes no sentido de que ambos são essencialmente rótulos de identificação que podem ou não ser usados para a autoidentificação. Embora uma identidade índia correntemente tenha significação política, até recentemente o termo (que se origina, como se sabe, de um erro histórico) foi apenas uma categoria genérica de identificação utilizada pelos brancos e não tinha relação com as identidades dos povos indígenas aos quais se referia. A analogia entre os conceitos de índio e caboclo é útil, pois a validade do termo índio há muito se estabeleceu e assim ajuda a compreender como um rótulo de identificação, semelhante ao de caboclo, ganhou significado concreto e foi aceito por quem o recebeu (LIMA, 1999, p.12, grifos originais, citado por ROCHA, 2017).

Goldman (2017) aponta como a formulação teórica da mestiçagem esteve associada a um projeto integracionista, que visava abarcar o contingente populacional resultante da mistura racial na formação da sociedade brasileira, diluindo as diferenças em torno de uma ideia de construção da nação.

Nesse contexto, sincretismo e mestiçagem foram pensados ora como obstáculos a serem superados para a constituição de uma identidade nacional fundamental para essa construção, ora como traços singulares que, ao contrário, possibilitariam a elaboração de uma identidade nacional ao mesmo tempo original e semelhante a de países mais tradicionais [...] (GOLDMAN, 2017, p.13).

Assim, as narrativas coloniais estabeleceram o lugar da diferença em torno do projeto de homogeneização de uma sociedade branca. No entanto, os diversos grupos sociais "assujeitados" conformaram distintos modos de articulação das suas identidades, negando muitas vezes a sua incorporação à unidade dominante enquanto expressão de uma "outridade" (KILOMBA, 2019, p.37). Nesse sentido, buscamos compreender como, a partir da performance realizada no culto aos caboclos, se ativa uma "cosmopolítica" específica, uma criação de mundos expressa num modo particular de articular as diferenças 
que "não pressupõe a homogeneização como horizonte da interação entre as diferenças" (GOLDMAN, 2017, p.16).

O que pretendemos ressaltar vai ao sentido de se lançar um olhar sobre os modos de ajuntamento de práticas afros e indígenas na configuração do repertório (TAYLOR, 2006) acionado no culto aos caboclos, buscando determinar a qualidade específica desta forma de "criar mundos" - baseada notadamente na capacidade de estabelecer "confluências" (SANTOS, 2015, p.89) na performance ritual - através do conceito de "relação afroindígena", uma proposta de compreensão das articulações de agenciamentos que:

[...] combinaram, por um lado, dimensões de diferentes pensamentos de origem africana com aspectos dos imaginários religiosos cristãos e do pensamento ameríndio e, por outro, formas de organização social tornadas inviáveis pela escravização com todas aquelas que puderam ser utilizadas, dando origem a novas formas cognitivas, perceptivas, afetivas e organizacionais. (GOLDMAN, 2014).

Quando atentamos a partir de índices da memória e atuação corporal aos modos de agenciamento da presença indígena no candomblé, expressa em diversos conhecimentos e práticas no culto aos caboclos, constatamos a utilização de um repertório configurado em elementos culturais indígenas, ainda que generalizante, no sentido em que são atribuídos a um "indígena" primordial. A partir da concepção de Diana Taylor (2006), compreendemos o termo repertório como um sistema de transmissão de conhecimento que se refere a encenações de memória corporal, performances, gestos, oralidade, movimentos, danças, músicas, cantos - conhecimentos pensados como efêmeros e não reprodutíveis, mas que podem ser concebidos como profundamente históricos:

Então, se nós pensarmos sobre o passado não apenas como cronológico e como algo que já foi, mas como algo vertical, uma forma diferente de armazenamento do que ainda está aqui, então performance é profundamente histórica. É iterativa, funções qualitativas recorrentes através das repetições, mas também quebrando com elas ${ }^{4}$. (TAYLOR, 2006, p.83 - tradução nossa).

\footnotetext{
${ }^{4}$ Do original - "So if we think about the past not only as chronological and as what is gone, but as also vertical, as a different form of storage of what's already here, then performance is deeply historical. Its iterative, recurrent quality functions through repeats, yet breaks out of them" (TAYLOR, 2006, p.3).
} 
Nesse sentido, uma reflexão sobre a composição desse repertório - uma modalidade de historicidade que localiza no presente os materiais necessários à compreensão de formas sociais de conhecimento transmitidas no tempo, bem como os modos pelos quais elas são ativadas na prática - se mostra viável para a compreensão da ação cosmopolítica da performance no processo de atualização de entidades espirituais. Em outras palavras, possibilita acessar a mobilização de uma motriz cultural indígena e nos permite pensar sobre o que acontece no seu encontro com princípios afro e que relaciona pessoas, entidades espirituais, lugares etc.

O encontro e as alianças contingenciais entre populações da diáspora africana e indígenas são o ponto de inflexão que marca a inserção dos caboclos nos candomblés. Essas são as "motrizes culturais" (LIGIÉRO, 2011) que constituem as características dessas entidades em uma relação de mediação entre agências de elementos afro e indígenas. Em algumas narrativas entre pessoas do candomblé de Santo Amaro, por exemplo, foram os caboclos que ensinaram aos orixás a ecologia das florestas sul-americanas, suas folhas, possibilitando a sua utilização nos rituais (SILVA, 2018). Encontramos na fala de muitos um encontro, não apenas entre pessoas, mas entre entidades, mundos cosmológicos, ocorrido no processo de reterritorialização dos africanos no Brasil, como aponta Mãe Julinha5: "Eles foram atacados, nas matas se esconderam e lá se encontraram com Ossain deram as mãos de amigos". Os caboclos são cultuados como os donos da terra, ancestrais aos quais se deve reverências, pois estavam aqui antes da chegada dos povos africanos trazidos como escravizados. Ponto de significação do culto aos caboclos, o encontro entre afros e indígenas é uma experiência narrada e atualizada na prática ritual, um evento histórico que pode ser pensado como performance.

Na perspectiva apresentada por Marilyn Strathern (2014), ao tomarmos um evento como performance, podemos compreendê-lo nos termos do que está registrado nas ações de quem o testemunha. Assim, interpretar o encontro como performance, evento reatualizado na prática ritual, significa enfatizar uma das dimensões de relações estabelecidas entre as agências de povos afro e indígenas. É compreendê-lo enquanto um modelo que confere significado à existência, uma história verdadeira e "sagrada" que relata como uma realidade passou a existir.

${ }^{5}$ Documentário. 15 anos de Senzala. São Paulo: Proext. NUAAB/USP. (2015). 
[...] Uma sucessão de deslocamentos, sendo cada uma delas uma substituição do que aconteceu anteriormente, e assim, em certo sentido, contém tanto o que veio antes quanto seus efeitos sobre a testemunha. Nesse sentido, cada imagem é uma nova imagem. Como consequência, o tempo não é uma linha que divide os acontecimentos; ele reside na capacidade de uma imagem evocar o passado e o futuro simultaneamente. (STRATHERN, 2014, p.215).

Nesse sentido, ao refletir sobre esse encontro e seus modos de interação, devemos nos preocupar menos com a origem da inserção dos caboclos nos candomblés e mais em investigar como os conteúdos de suas ações são significados na prática, pois "em processos históricos específicos, a tradição é tomada como estímulo para a inovação e antigas significações são atribuídas a elementos novos" (PARÉS, 2007). Ao restaurar os comportamentos, a comunidade religiosa do candomblé (humanos e entidades) elabora modos de relacionamento e ajuntamentos com uma cultura indígena vivificada na ação dos espíritos caboclos, mobilizando idiossincrasias na formulação de uma caracterização específica, guardada na memória dos terreiros e na memória dos espíritos e reativada através da performance ritual, e que apresentam a identidade indígena desfazendo-se das classificações de miscigenação.

Os caboclos que se manifestam nos terreiros de candomblé não são apenas símbolos que representam a experiência do contato entre afros e indígenas; eles agenciam essa interação, que há "500 anos" não deixa de estabelecer-se e atualizam as forças motrizes que movimentam e redefinem as suas características nos rituais do candomblé. Seguindo a afirmação expressa pelos adeptos do candomblé, mas também pela própria entidade em sua apresentação: o caboclo é um índio!

\section{Performance ritual}

Embora o ritual de culto aos caboclos suscite aspectos propriamente performáticos, expressos em danças, cantigas, toques, gestualidades etc., pretendo aqui conceber a performance como uma perspectiva epistemológica específica, sublinhando a possibilidade de analisar eventos enquanto/como performance (STRATHERN, 2014; TAYLOR, 2013). Assim, justapondo os conceitos de encorporação e incorporação, novos sentidos podem ser explorados na compreensão da seleção dos materiais utilizados na restauração dos comportamentos dos caboclos. 
Como na performance, no transe e na incorporação, o "eu" é formado por múltiplos "eus", são também múltiplas as agências na formulação das características, visíveis ou não, esperadas culturalmente, especificadas e que contribuem significativamente para identificar as entidades, que "podem criar múltiplas versões de si mesmas, então torna-se menos importante localizar a versão original do que analisar suas sequências" (BLANES; ESPIRITO-SANTO, 2014). Como as "práticas encorporadas ${ }^{6 "}$ (TAYLOR, 2006) tornam o passado válido como recurso político no presente ativando simultaneamente múltiplos processos, elas podem ser sobre algo que nos ajude a entender o passado, reativando ideias e cenários e representando-os no presente através de mecanismos físicos de encenação que podem manter vivas infraestruturas organizacionais. No caso, realizam uma dinâmica própria da relação afroindígena, cuja mistura não dissolve as características de cada elemento e que se constitui em uma prática, um saber fazer, uma episteme. "Pessoas, ancestrais e deuses participam simultaneamente "tendo sido", "sendo" e "vindo a ser" [...] as tiras de comportamento são reencenadas muitas vezes, transmitidas através de gerações com pequenas variações acidentais ${ }^{7}$ (SCHECHNER,1985, p.36 - tradução nossa).

O sentido temporal no qual os materiais são selecionados e utilizados não é apenas "do passado para o presente", mas opera de maneira reflexiva. Mais do que "reencenar" um passado ao mobilizar materiais significativos através de comportamentos restaurados, as performances também criam esse passado. Elas permitem a possibilidade de "ser algo que não foi", atuam hoje "como se" ontem fosse assim, e nesse sentido reciclam a experiência humana. Assim, as performances têm também a capacidade de "mudar o passado", recriá-lo, ou pelo menos conferir-lhe novos significados ou expressões ao representá-lo no presente, e talvez nisso residam as margens para transformações dos rituais em termos considerados pela oposição tradição versus mudanças. Os rituais são variações, no entanto, como propõe Goldman (2014, p.6), “[...] não se trata de encarar as variações nem como variedades irredutíveis umas às outras, nem como emanações de um universal qualquer conectando entidades homogêneas: as conexões se dão entre heterogêneos enquanto heterogêneos".

Diana Espírito-Santo (2014) aponta que os espíritos devem trabalhar dentro das fronteiras conceituais de um inconsciente individual e coletivo:

\footnotetext{
${ }^{6}$ Embodied practices

7 People, ancestors and gods participated in simultaneously having been, being, and becoming. This strips of behavior were replayed many times. [...] transmitted across many generations with few accidental variations.
} 
[...] de modo a estruturar a ontologia dos espíritos neste universo, é igualmente necessário decifrar uma conceitualização local da consciência humana e sua capacidade de, literalmente, engendrá-los. Ou seja, as realidades dos espíritos não são autônomas, mas estão atadas às mentes daqueles que os veem. (ESPÍRITO-SANTO, 2014, p.71).

Os rituais são elaborados em uma relação em que, por um lado, certas disposições orientam os meios de realização das atividades religiosas em um contexto específico, por outro, os agenciamentos das entidades conferem vitalidade ao conjunto de práticas realizadas com o objetivo de ativar sua manifestação. Se a incorporação é uma das maneiras de o caboclo aparecer, há ainda um outro conjunto de práticas encorporadas mobilizadas para torná-lo reconhecido como índio. Os elementos acionados no repertório ritual são transmitidos de modo seletivo e ininterrupto, transformando determinadas características em elementos significativos da identidade. Os espíritos são como lembramos e como eles se lembram também, mas os "modos de ser" da vida social dos caboclos na prática do ritual podem ser compostos por sequências de comportamentos que podem ser rearranjadas ou reconstruídas, pois são independentes dos sistemas causais que os trouxeram à existência.

José Sérgio de Oliveira (2001) apresenta em sua dissertação de mestrado uma formulação sobre a construção do que chamou de "corpo-caboclo", que nos permite "compreender quais os elementos que possibilitam o "eu" - aquele que pratica o culto -, fazer uso específico do seu corpo para configurar-se no "outro" - o caboclo". Para o autor, os traços distintivos que integram o comportamento dos caboclos, agindo em conformidade aos códigos rituais, são resultantes de diversos processos individuais e coletivos, sendo necessário considerar imagens, representações e "símbolos oriundos da vivencia pessoal e religiosa que integram a memória dos praticantes do culto" (idem, p.61), com especial atenção aos sonhos que podem revelar as características da entidade, prever acontecimentos, orientar sobre fundamentos, revelar a corporeidade da entidade e até mesmo desencadear a incorporação:

Portanto, da mesma forma que os sonhos representam o acesso ao conhecimento posto em prática, também funcionarão como estímulos à construção da corporeidade dos caboclos, pois seus conteúdos podem revelar formas de agir de determinada entidade, sua vestimenta, formas de uso da fala, seu temperamento, forças da natureza às quais está ligado, entre outros elementos que formam o corpo-caboclo. (OLIVEIRA, 2001, p.69). 
O caboclo é um construtor de redes, capaz de "fazer acontecimentos" (STENGERS, 2017). Assim, atribuo à performance o potencial de criar um mundo no qual se realiza um "processo de reconstrução da indianidade", a afirmação de uma (id)entidade espiritual e também cosmopolítica, no sentido em que se refere a uma nova ontologia, um cosmo, que difere do reconhecimento da política do que seria um "índio".

\section{Cosmopolítica da Performance}

Para ser reconhecido como índio, os caboclos mobilizam um propósito de recuperação da indianidade acionando rupturas das unidades fundantes da identidade no mundo ocidental. Parafraseando criativamente a reflexão de Carvalho (2011) sobre o processo de reconstrução da indianidade concernente ao Nordeste, nos terreiros, os caboclos mobilizam a categoria de índios misturados a índios performados, possuidores de uma performance que se pode considerar índio. No caso especificado, esse trajeto também se associa a uma recuperação de direitos históricos ou retomadas de territórios, como em relação aos processos dos índios regimados, no entanto, a ação cosmopolítica analisada se relaciona à mobilização identitária apoiando-se em um conjunto de preceitos afro-religiosos.

Se entre os índios regimados "o primeiro passo para assegurar o reconhecimento é recorrer a uma liderança tradicional" (CARVALHO, 2011, p.4) e não raro essa liderança seja mitificada, nos terreiros são os próprios caboclos, encantados, que se manifestam realizando ações, principalmente através das cantigas, orientando para o "reconhecimento da aldeia".

Em trabalhos anteriores (SILVA, 2018), apresentei etnobiografias que demonstravam como os caboclos podem ser fundamentais nas trajetórias religiosas de adeptos no processo de consolidação de seus terreiros. E como os caboclos atualizam a descendência através de linhagens que relacionam parentescos, por exemplo, caboclos que já se manifestaram anteriormente em algum parente e que agora se manifestam através de outro médium, rodante, da mesma família.

A descoberta da aldeia através do "encantado ancestral", o caboclo da família, irradia as formas de aliança do grupo e possibilita a associação de diversos caboclos numa mesma aldeia. Como expressam algumas cantigas, uma das formas da "ciência dos caboclos": "Eu disse camarada que eu vinha, na sua aldeia, camarada, um dia!" “Lá na aldeia, lá na aldeia, lá na aldeia, 
caboclo, lá na aldeia!". São composições, cujos autores, os caboclos, os donos das cantigas, transmitem uma mensagem afirmando a sua nação, cujo termo é aqui pensado diferindo da sua utilização para designar nações de candomblé. Os caboclos dão o nome. Muitas vezes ajoelhados frente aos atabaques, durante a "salva", a primeira cantiga. O caboclos nos candomblés definem-se, ao apresentarem seus nomes, numa dimensão coletiva da sua individualidade. Existem muitos Sete Flechas, Sultão das Matas, Laje Grande e/ou outros caboclos, mas cada um é único, na relação com o seu rodante, e também no seu processo de "individuação biográfica" (CARDOSO, 2012).

Nesse processo de identificação, estabelecem-se alianças indígenas. Caboclos podem trazer suas cantigas para outros caboclos. Um caboclo boiadeiro afirmou que a sua salva havia sido dada pelo Sultão das matas de outra mãe de santo. O caboclo de uma mãe de santo pode muitas vezes trazer a salva dos caboclos dos filhos de santo dessa família na primeira vez que se manifestam e se apresentam publicamente. São modos de aliança indígena que possibilitam o acesso ao mundo dos encantados e a manifestação através da ciência dos caboclos. Embora haja um tempo ritual codificado para a apresentação do caboclo, em alguns casos eles "podem passar" antes desse tempo, através do caminho aberto por outros caboclos.

O processo de identificação indígena exacerba algumas características. Os elementos acionados no repertório ritual são transmitidos de modo seletivo e ininterrupto, transformando determinados atos e personagens em símbolos significativos da identidade. No entanto, é neste ponto, naquilo que Carvalho classificou como a radicalização da identidade étnica, que a homologia que traçamos entre os modos de reconhecimento mais se afastam, na relação com os seus contextos específicos. No processo de radicalização da identidade étnica entre os indígenas do Nordeste, entre os Kiriri, especificamente, há uma “atribuição de conotação negativa às práticas de caráter doméstico de incorporação xamanística, eventualmente associada a aspectos de tradição africana" (CARVALHO, 2011, p.13), buscando demonstrar costumes próprios de índios. Por outro lado, como aponta Flores (2017, p.48), nos terreiros, “a religião de matriz africana é componente crucial para a elaboração indígena".

\section{Conclusões}

Os "modos de ser" da vida social dos caboclos na prática do ritual são compostos por sequências de comportamentos que podem ser rearranjadas ou 
reconstruídas, pois são independentes dos sistemas causais que os trouxeram a existência, o que Schechner (1985) chamou de comportamentos restaurados:

\begin{abstract}
"comportamento restaurado" 8 é simbólico e reflexivo: não é vazio, mas um comportamento carregado de significados de transmissão multivocais. Estes termos difíceis expressam um simples princípio: $\mathrm{O}$ "self" pode agir em/como outro; $\mathrm{O}$ "self" individual ou trasindividual é um papel ou um conjunto de papéis. (SCHECHNER, 1985, p.36) 9 .
\end{abstract}

Ao ativar determinados saberes, o caboclo define sua identidade indígena e transmite conhecimento social e memória através de um complexo de gestos e modos de ser operados na relação entre pessoas e espíritos e que podem ser sobre algo que nos ajude a entender a identidade indígena através de "um repertório de conhecimento encorporado, uma aprendizagem no e através do corpo, [...] como um meio de criar, preservar e transmitir conhecimento; o que constitui a performance" (SCHECHNER, 2013, p.28).

Os rituais são elaborados nesta relação: por um lado, certas disposições orientam os meios de realização das atividades religiosas em um contexto específico conformando uma identidade indígena, por outro, as proposições das entidades conferem vitalidade ao conjunto de práticas realizadas com o objetivo de ativar sua manifestação. Assim, os caboclos são compreendidos, em uma determinada perspectiva, como entidades espirituais sociais.

Assim, analisando alguns momentos rituais do culto aos caboclos nos terreiros, em uma chave homóloga à transformação dos "índios misturados" em "regimados" (CARVALHO, 2011), no processo de reconhecimento da identidade indígena, sendo as etapas desse processo 1) recorrer a uma liderança tradicional, 2) a "descoberta da aldeia", 3) apoio "político" externo e interno, e 4) a radicalização da identidade étnica, então através da performance, os caboclos operam um engajamento na transformação do significado de uma categoria antes utilizada para designar o resultado da "mestiçagem", ou seja, de "índio misturado" para uma nova identificação através da performance, ou seja, um "índio performado".

\footnotetext{
${ }^{8}$ Em inglês "restored behaviour". Optamos pela tradução restaurado, no entanto, alguns autores, como Diana Taylor $(2013,2013 b)$, utilizam a tradução reiterado. Concordamos que ambos os sentidos estão presentes no conceito: tanto o de algo repetido constantemente (reiterado), quanto de algo que é renovado através da ação (restaurado).

9 Restored behavior is symbolic and reflexive: not empty but loaded behavior multivocally broadcasting significances. These difficult terms express a single principle: The self can act in/as another; the social or transindividual self is a role or set of roles.
} 


\section{Referências}

ALARCON, Daniela Fernandes.

(2013). O retorno da terra: As retomadas na aldeia Tupinambá da Serra do Padeiro, sul da Bahia. Dissertação de mestrado. Instituto de Ciências Sociais, UNB.

BLANES, Rui; ESPÍRITO SANTO, Diana (eds). (2014). The social life of spirits. Chicago and London: The University of Chicago Press.

BLASER, Mario.

(2018). Uma outra cosmopolítica é possivel?. R@U,vol.10,n.2, p. 14-42.jul./dez.

CARDOS0, Vânia Zikan.

(2012). Marias: a individuação biográfica e 0 poder das estórias. In: GONÇALVES, M. A. (Org.); MARQUES, R. (Org.); CARDOSO, Vânia Zikan. (Org.). Etnobiografia: Subjetivação e etnografia. Rio de Janeiro: 7 Letras.

CARVALH0, Maria Rosário de.

(2011). De índios "misturados" a índios "regimados". In: CARVALHO, Maria Rosário de. et al. (org.). Negros no mundo dos índios: Imagens, reflexos, alteridades. Natal, Editora da UFRN, p. 337-358.

ESPÍRITO SANTO, Diana.

(2014). Plasticidade e pessoalidade no espiritismo crioulo cubano. In: Mana. Estudos de Antropologia Social, vol. 20, n. 1, p. 63-93.

FLAKSMAN, Clara.

(2017). Enredo de santo e sincretismos no candomblé de Salvador, Bahia. Revista de @ntropologia da UFSCar, São Carlos, v.9, n.2, p.153-170.

FLORES, Luisa. Dias.

(2017). A guerra comancheira: contribuições a uma antropologia afroindígena. Revista de @ntropologia da UFSCar, São Carlos, v.9, n.2, p.43-63.

GOLDMAN, Mácio.

(2017). Contradiscursos Afroindígenas sobre Mistura, Sincretismo e Mestiçagem Estudos
Etnográficos.Revistade @ntropologia da UFSCar, São Carlos, v.9, n.2, p.11-28.

(2016). Cosmopolíticas, etno-ontologías y otras epistemologías. Cuadernos de Antropología Social. v.44.

(2015). "Quinhentos anos de Contato": Por uma Teoria Etnográfica da (Contra)Mestiçagem. Mana, vol. 21, n. 3, p. 641-659.

(2014). A relação afroindígena. Cadernos de campo, n. 23. São Paulo. p. 213-222.

KILOMBA, Grada.

(2019). Memórias da plantação: Episódios de racismo cotidiano. Tadução: Jess Oliviera.. Rio de Janeiro: Cogobó.

LIGIÉR0, Zeca.

(2011). 0 conceito de 'motrizes culturais' aplicado às práticas performativas de origens africanas na diáspora americana. Revista Pós Ciências Sociais. v. 8 n. 16.

LIMA, Deborah de Magalhães.

(1999). A Construção Histórica do Termo Caboclo: sobre estruturas e representações sociais no meio rural amazônico. In: Novo Cadernos NAEA, vol 2, n.2, p. 05-32.

OLIVEIRA, José Sérgio de.

(2001). Xetro, Marrombaxetro, Caboclo! A Construção do Corpo caboclo nos Candomblés da Cidade de Cachoeira - Ba. Dissertação de mestrado apresentada ao Programa de Pósgraduação em Artes Cênicas da UFBA.

PARÉS, Nicolau.

(2007). A formação do Candomblé: história e ritual da nação jeje na Bahia, 2.ed.rev., Campinas, SP, Editora da Unicamp.

ROCHA, Cinthia Creatini da.

(2017). Mistura, alteridade e identidade: reflexões sobre o campo relacional entre os Tupinambá de Olivença. ANPOCS, ST 01 Antropologias Afroindígenas: Contradiscursos e Contramestiçagens. 
SANTOS, Antônio Bispo dos (Nêgo Bispo).

(2015). Colonização, Quilombos - modos e significações. Brasília: INCT.

SCHECHNER, Richard.

(2013). "Pontos de contato" revisitados. In: Revista de Antropologia da USP, Departamento de Antropologia da Faculdade de Filosofia, Letras e Ciências Humanas da Universidade de São Paulo. vol. 56, n. 2, jul-dez, São Paulo, SP.

(1985). Between theater and anthropology. Philadelphia: The University of Philadelphia Press.

SILVA, Fábio Alex Ferreira da.

(2018). “Eu vou ali e volto já, daqui a pouco tô no mesmo lugar": performances e agências sociorrituais no culto aos caboclos em Santo Amaro-BA. Dissertação de mestrado apresentada à Universidade Federal do Recôncavo da Bahia.

STENGERS, Isabelle.

(2014). La propuesta cosmopolítica. Revista Pléyade 14. p. 17-41. julio-diciembre.
STRATHERN, Marylin.

(2014). Artefatos da história: os eventos e a interpretação de imagens. In: STRATHERN, Marylin. O efeito etnográfico e outros ensaios. São Paulo: Cosac Naify.

TAYLOR, Diana.

(2013). O arquivo e o repertório: performance e memória cultural nas Américas. Tradução de Eliana Lourenço de Lima Reis. Belo Horizonte: Editora UFMG.

(2006). Performance and/as History. The Drama Review. vol. 50, n.1.

\section{Recebido em}

julho de 2021

\section{Aprovado em}

dezembro de 2021 